\title{
Efek Samping KB IUD (Nyeri Perut) dengan Kelangsungan Penggunaan KB IUD
}

\author{
Yuniasih Purwaningrum ${ }^{*}$ \\ ${ }^{1}$ Prodi Kebidanan Jember, Indonesia \\ Email: yunipurwaningrum268@gmail.com*
}

\begin{abstract}
Abstrak
Visi program KB nasional yaitu mewujudkan "Keluarga Berkualitas 2015" sasarannya adalah terkendalinya pertumbuhan penduduk dan meningkatkan penggunaan metode kontrasepsi yang rasional, efektif dan efisien salah satunya KB IUD, namun dalam penggunaan KB IUD dapat menimbulkan efek samping salah satunya nyeri perut. Di Puskesmas Wringin Kabupaten Bondowoso akseptor KB IUD yang mengalami efek samping sebesar 25\% (1800 dari 7202 akseptor) padahal target yang harus dicapai hanya 10\% dari akseptor. Efek samping KB IUD (nyeri perut) bisa ditanggulangi asalkan akseptor mau mengkonsultasikan masalah yang dihadapi kepada petugas kesehatan. Tujuan penelitian ini untuk menguji hubungan efek samping KB IUD (nyeri perut) dengan kelangsungan penggunaan KB IUD.Desain penelitian yang digunakan adalah penelitian kolerasi dengan pendekatan cross secsional dengan menggunakan studi retrospektif, data yang diambil dari data dukomen pada bulan Juli sampai dengan bulan September 2015 dengan populasi 34 akseptor dan jumlah sampel 31 responden menggunakan teknik random sampling, analisa data menggunakan uji stastistik Chi kuadrat dan tempat penelitian dilakukan di Puskesmas Wringin.Hasil Penelitian menunjukan bahwa 58,06\% akseptor mengalami efek samping KB IUD (nyeri perut) kadang- kadang dan 41,94\% akseptor yang sering mengalami. Sedangkan dari 48,3\% akseptor KB IUD yang tetap memakai dan 51,61\% akseptor KB IUD yang drop out. Setelah dilakukan uji stastistik didapatkan hasil $X^{2}$ hitung 2,781821.Kesimpulan $X^{2}$ hitung lebih kecil dari $X^{2}$ tabel Chi Kuadrat maka Ho diterima yang artinya tidak ada hubungan efek samping KB IUD (nyeri perut) dengan kelangsungan penggunaan KB IUD. Saran yang diberikan untuk segera kontrol ulang ke petugas kesehatan bila mengalami keluhan.
\end{abstract}

Kata kunci : Efek samping KB IUD, nyeri perut, kelangsungan KB

\section{Pendahuluan}

Keberhasilan program Keluarga Berencana $(\mathrm{KB})$ yang di kenal sebagai gerakan keluarga berencana nasional, selama pembangunan Jangka Panjang Pertama (PJP I) telah membawa pengaruh yang besar terhadap kegiatan program Keluarga Berencana (KB) pada masyarakat umum dan diterima di mata dunia Internasional. Tujuan dari program KB dimaksudkan untuk membantu pasangan atau perorangan dalam mencapai tujuan reproduksi secara bertanggung jawab untuk membangun keluarga yang berkualitas. Tujuan tersebut sesuai dengan visi program KB Nasional yaitu mewujudkan "Keluarga Berkualitas 2015". Sasarannya adalah terkendalinya pertumbuhan penduduk dan meningkatnya keluarga berkualitas ditandai dengan meningkatnya penggunaan metode kontrasepsi yang rasional, efektif dan efisien (BKKBN, 2004).

Kontrasepsi adalah upaya mencegah kehamilan yang bersifat sementara atau menetap. Kontrasepsi dibagi dalam 2 metode yaitu dengan metode sederhana dan metode modern. Metode sederhana dibagi menjadi 2 yaitu, dengan menggunakan alat dan tanpa alat. Tanpa menggunakan alat yaitu, KB alamiah (metode kalender, metode suhu basal, metode lendir serviks, Metode Amenorhea Laktasi /MAL), coitus interuptus atau senggama terputus. Sedangkan menggunakan alat yaitu meliputi kondom, diafragma dan spermisid. Metode modern terdiri dari pil, IUD, suntik, implan atau susuk, kontrasepsi mantap (Tubektomi dan Vasektomi) (Hanafi, 2004).

Metode kontrasepsi khususnya IUD memenuhi syarat kontrasepsi yang baik diantaranya sangat efektif, reversible, berjangka panjang, dapat dipakai semua perempuan usia reproduksi, murah dan cocok untuk ibu menyusui, IUD berbentuk kecil terbuat dari kerangka plastik yang fleksibel, berbentuk huruf $\mathrm{T}$ diselubungi oleh kawat halus terbuat dari tembaga $(\mathrm{Cu})$ dan dipasang dalam rahim (Syaifudin, 2003).

Penggunaan metode kontrasepsi dipengaruhi oleh beberapa faktor. Adapun faktor-faktor yang mempengaruhi seorang dalam menggunakan alat kontrasepsi menurut Bruce yang dikutip oleh Ambar Widaningrum 
diantaranya pengalaman berKB, peran pengambil keputusan, adanya putus pakai, status sosial dalam masyarakat, faktor demografi tempat tinggal dan aktifitas bermasyarakat (Widaningrum,1999).

Setiap metode kontrasepsi mempunyai masa efektif yang berbeda, begitu pula dengan IUD, IUD mempunyai masa efektif yang lama sampai 10 tahun sehingga alat kontrasepsi IUD mempunyai efek samping. Efek samping yang mungkin terjadi ialah gangguan haid, infeksi keputihan, ekspulsi IUD, perforasi, rasa mulas/nyeri/kram pada perut bagian bawah, rasa nyeri pada alat kelamin suami (DepKes RI, 2002).

Kebanyakan kelangsungan pemakaian alat kontrasepsi di daerah pedesaan alasan berhenti menggunakan alat kontrasepsi setelah pemakaian karena ingin tambah anak, berikutnya ganti cara kontrasepsi yang sesuai dan gangguan kesehatan. Widaningrum (1999) menyebutkan satu dari sekian banyak pemutusan pemakaian kontrasepsi adalah persepsi terjadinya efek samping.

Beberapa studi menyimpulkan bahwa pelayanan yang baik merupakan faktor penting dalam penerimaan dan keberlangsungan pemakaian kontrasepsi, klien akan menyalahkan problem-problem atau efek samping kesehatan yang muncul sebagai akibat dari kontrasepsi yang mereka pakai. Reaksi ini muncul sebagai akibat miskinnya konsultasi dan informasi tentang metode kontrasepsi yang dipakai (Widaningrum, 1999). Agar para provider mampu menyampaikan informasi atau KIE (Komunikasi Informasi Edukasi) kepada klien atau para akseptor maka kegiatan sosialisasi harus di lakukan di kalangan provider dan diharapkan kesadaran para provider untuk menyampaikan kepada para klien atau akseptor $\mathrm{KB}$, dengan mengacu pada pola pemakaian kontrasepsi yang rasional, efektif dan efisien, di harapkan angka drop out, keluhan mengenai efek samping/ masalah kesehatan dapat ditanggulangi.

Berdasarkan Survei Demografi dan Kesehatan Indonesia (SDKI) 2012, sebanyak 62 persen peserta KB menggunakan alat kontrasepsi modern dan tradisional. Pengguna IUD baru 4 persen, susuk 3 persen, suntik 32 persen, dan pil 14 persen. Hal ini menunjukan bahwa penggunalan IUD masih sangat rendah. Salah satu tolak ukur dari kualitas pemakaian alat kontrasepsi dalam hal ini kontrasepsi IUD dapat dilihat dari tingkat kelangsungannya. Adapun berbagai alasan yang di kemukakan oleh para akseptor KB, mereka berhenti menggunakan alat kontrasepsi setelah 12 bulan pemakaian karena kegagalan kontrasepsi, ingin hamil, ingin ganti cara dan alasan lainnya. Sedangkan mereka yang berhenti setelah 5 tahun pemakaian, alasan utama yang dikemukakan dalam SDKI 2012 adalah karena efek samping $(14,4 \%)$ dan kasus efek samping untuk IUD sendiri adalah sebesar 19.232 kasus $(27,7 \%)$.

Menurut data register yang diambil dari tahun 2015 di wilayah kerja Puskesmas Wringin Kabupaten Bondowoso akseptor KB IUD mengalami efek samping sebesar $25 \%$ (1800 dari 7202 akseptor) dan yang tidak mengalami efek samping sebesar $75 \%$ (5401 dari 7202 akseptor) Berdasarkan latar belakang di atas menunjukkan angka kejadian efek samping pada akseptor IUD sebanyak $25 \%$ padahal target yang hendak dicapai tahun 2015 untuk kejadian efek samping adalah $10 \%$, oleh karena itu perlu kiranya di kaji kejadian efek samping KB IUD terhadap kelangsungan penggunaan KB IUD.

\section{Metode penelitian}

Desain penelitian ini adalah desain penelitian korelasi dengan pendekatan cross sectional dengan menggunakan studi retrospektif, yaitu suatu penelitian dimana variabel-variabel yang termasuk efek diobservasi sekaligus pada waktu yang sama. Populasi pada penelitian ini adalah seluruh akseptor KB IUD yang mengalami efek samping nyeri perut di wilayah Puskesmas Wringin Kabupaten Bondowoso yang berjumlah 34 akseptor dan berdasarkan rumus diambil sampel sebanyak 31 akseptor.

Teknik sampling pada penelitian ini menggunakan random sampling yaitu dengan mengambil sampel secara acak.

Hasil perolehan data dimasukkan pada lembar tabulasi data dan dianalisa dengan uji stastistik Chi Kuadrat.

\section{Hasil dan pembahasan}

\subsection{Hasil penelitian}


Pada penelitian ini, Jumlah akseptor KB IUD yang mengalami efek samping (nyeri perut) ditunjukkan pada tabel 1 .

Tabel 1. Jumlah Akseptor KB IUD yang Mengalami Efek Samping (Nyeri Perut) Bulan Juli - September Tahun 2015 Di Wilayah Kerja Puskesmas Wringin Kabupaten Bondowoso

\begin{tabular}{clc}
\hline No & Nama desa & $\begin{array}{c}\text { Jumlah akseptor } \\
\text { KB IUD yang } \\
\text { mengalami } \\
\text { efek samping } \\
\text { (nyeri perut) }\end{array}$ \\
\hline 1 & Wringin & 6 \\
2 & Sumber & 2 \\
3 & Canting & 4 \\
4 & Banyu Wulu & 2 \\
5 & Banyu Putih & 3 \\
6 & Jatisari & 1 \\
7 & Bukor & 3 \\
8 & Glingseran & 2 \\
9 & Ambulu & 2 \\
10 & Gubrih & 1 \\
11 & Jati Tamban & 3 \\
12 & Ampelan & 3 \\
13 & Jambe Wungu & 2 \\
& Sumber & \\
\hline & Malang & Jumlah \\
\hline
\end{tabular}

Dari tabel 1. dapat diketahui bahwa jumlah akseptor KB IUD yang mengalami efek samping (nyeri perut) bulan Juli sampai dengan bulan September 2015 di wilayah kerja Puskesmas Wringin Kabupaten Bondowoso terdapat 34 responden. Dari populasi tersebut diperoleh sampel 31 responden.

Selain itu ada beberapa data khusus yang juga diteliti, yaitu efek samping (nyeri perut), kelangsungan penggunaan KB IUD dan hubungan efek samping KB IUD (nyeri perut) dengan kelangsungan penggunaan $\mathrm{KB}$ IUD.

Tabel 2. Distribusi Frekuensi Jumlah Akseptor KB IUD yang Mengalami Efek Samping (Nyeri Perut) yang Terjadi Kadang-Kadang dan yang Sering di Wilayah Kerja Puskesmas Wringin Kabupaten Bondowoso Tahun 2015

\begin{tabular}{lcc}
\hline $\begin{array}{c}\text { Efek samping } \\
\text { (nyeri perut) }\end{array}$ & Jumlah & Persentase \\
\hline Kadang-kadang & 18 & $58,06 \%$ \\
Sering & 13 & $41,94 \%$ \\
\hline \multicolumn{1}{c}{ Jumlah } & 31 & $100 \%$ \\
\hline
\end{tabular}

Berdasarkan tabel 2. menunjukkan bahwa dari 31 sampel akseptor KB IUD yang mengalami efek samping (nyeri perut) kadang-kadang sebesar 18 responden $(58,06 \%)$ dan akseptor KB IUD yang mengalami efek samping (nyeri perut) yang sering sebesar 13 responden $(41,94 \%)$.

Tabel 3. Distribusi Frekuensi Kelangsung -an KB IUD Yaitu Yang Tetap Memakai Dan Yang Drop Out Di Wilayah Kerja Puskesmas Wringin Kabupaten Bondowoso Tahun 2015

\begin{tabular}{lcc}
\hline $\begin{array}{c}\text { Kelangsungan } \\
\text { penggunaan } \\
\text { KB IUD }\end{array}$ & Jumlah & Persentase \\
\hline Tetap memakai & 15 & $48,39 \%$ \\
Drop out & 16 & $51,61 \%$ \\
\hline \multicolumn{1}{c}{ Jumlah } & 31 & $100 \%$ \\
\hline
\end{tabular}

Berdasarkan tabel 3. menunjukkan bahwa dari 31 sampel akseptor KB IUD di wilayah kerja Puskesmas Wringin Kabupaten Bondowoso yang tetap memakai 15 responden $(48,39 \%)$ yang drop out sebesar 16 responden $(51,61 \%)$. 
Tabel 4. Tabel Kontingensi Efek Samping KB IUD (Nyeri Perut) dengan Kelangsungan Penggunaan KB IUD Di Wilayah Kerja Puskesmas Wringin Kabupaten Bondowoso Tahun 2015

\begin{tabular}{cccc}
\hline \multirow{2}{*}{$\begin{array}{c}\text { Efek } \\
\text { samping } \\
\text { (nyeri } \\
\text { perut) }\end{array}$} & \multicolumn{2}{c}{$\begin{array}{c}\text { Kelangsungan } \\
\text { Penggunaan KB }\end{array}$} & \\
\cline { 2 - 3 } & $\begin{array}{c}\text { Tetap } \\
\text { IUemakai }\end{array}$ & $\begin{array}{c}\text { Drop } \\
\text { out }\end{array}$ & \\
\hline $\begin{array}{c}\text { Kadang- } \\
\text { kadang }\end{array}$ & 11 & 7 & 18 \\
Sering & 4 & 9 & 13 \\
\hline Jumlah & 15 & 16 & 31 \\
\hline
\end{tabular}

Berdasarkan tabel 4. menunjukkan bahwa akseptor yang mengalami efek samping (nyeri perut) kadang-kadang 11 responden yang masih tetap memakai dan 7 responden yang drop out, sedangkan akseptor yang mengalami efek samping (nyeri perut) yang sering 4 responden tetap memakai dan 9 responden yang drop out.

Kemudian dilakukan penghitungan sebagai berikut :

\begin{tabular}{cccc}
\hline \multirow{2}{*}{$\begin{array}{c}\text { Efek } \\
\text { samping } \\
\text { (nyeri }\end{array}$} & \multicolumn{2}{c}{\begin{tabular}{c}
\multicolumn{2}{c}{ Kelangsungan } \\
Pengunaan KB
\end{tabular}} & \\
\cline { 2 - 3 } perut) & $\begin{array}{c}\text { Tetap } \\
\text { memakai }\end{array}$ & $\begin{array}{c}\text { Drop } \\
\text { out }\end{array}$ & \\
\hline Kadang- & $11(\mathrm{a})$ & $7(\mathrm{~b})$ & 18 \\
kadang & $4(\mathrm{c})$ & 9 (d) & 13 \\
Sering & & & \\
\hline \multicolumn{1}{c}{ Jumlah } & 15 & 16 & 31 \\
\hline
\end{tabular}

Penghitungan :

$f h=\frac{\text { JumlahBaris }}{\text { jumlahSemua }} x$ JumlahKolom

\begin{tabular}{|c|c|c|c|}
\hline \multirow{2}{*}{$\begin{array}{c}\text { Efek } \\
\text { samping } \\
\text { (nyeri } \\
\text { perut) }\end{array}$} & \multicolumn{2}{|c|}{$\begin{array}{c}\text { Kelangsungan } \\
\text { Penggunaan KB } \\
\text { IUD } \\
\end{array}$} & \multirow[t]{2}{*}{ Jumlah } \\
\hline & $\begin{array}{c}\text { Tetap } \\
\text { memakai }\end{array}$ & $\begin{array}{c}\text { Drop } \\
\text { out }\end{array}$ & \\
\hline $\begin{array}{l}\text { Kadang- } \\
\text { kadang }\end{array}$ & 8,71 (a) & $\begin{array}{c}9,29 \\
\text { (b) }\end{array}$ & 18 \\
\hline Sering & 6,29 (c) & $\begin{array}{l}6,71 \\
(\mathrm{~d})\end{array}$ & 13 \\
\hline Jumlah & 15 & 16 & 31 \\
\hline
\end{tabular}

Penghitungan :

$$
\begin{aligned}
& X^{2}=\frac{(f o-f h)^{2}}{f h} \\
& X^{2}=X^{2} a+X^{2} b+X^{2} c+X^{2} d \\
& =2,781821
\end{aligned}
$$

Setelah dilakukan uji statistik ChiKuadrat dengan taraf signifikan 0,05 didapatkan $X^{2}$ sebesar 2,781821 sedangkan $X^{2}$ tabel Chi-Kuadrat dengan d.b $=1$ sebesar 3,481. Jadi didapatkan hasil $X^{2}$ hitung lebih kecil dari $X^{2}$ tabel Chi- Kuadrat maka hipotesa Ho diterima.

Kesimpulan yang diambil adalah efek samping (nyeri perut) tidak ada hubungan yang signifikan dengan kelangsungan penggunaan KB IUD. Berdasarkan kesimpulan tersebut maka tidak dilakukan uji Koefisiensi Kontingensi.

\subsection{Pembahasan}

Berdasarkan dari hasil penelitian padajumlah akseptor KB IUD yang mengalami efek samping (nyeri perut) kadang-kadang berjumlah 18 akseptor $(58,06 \%)$ dan jumlah akseptor KB IUD yang mengalami efek samping (nyeri perut) yang sering berjumlah 13 akseptor $(41,94 \%)$.

Nyeri perut / rasa mules / kram perut bagian bawah adalah rasa nyeri yang disebabkan karena adanya efek samping pemasangan IUD yang terjadi selama dan sesudah pemasangan dilakukan.

Mekanisme kerja IUD yaitu melakukan insersi IUD ke dalam rahim sehingga dapat menghambat kemampuan sperma untuk masuk ke tuba falopi, mempengaruhi fertilitas sebelum ovum mencapai kavum uteri dan IUD berkerja terutama mencegah sperma sulit masuk ke dalam alat reproduksi perempuan dan mengurangi kemampuan sperma untuk fertilitas sehingga mencegah implantasi sel telur dalam uterus.

Gejala dan keluhan yang dialami antara lain, (1) rasa mules didaerah perut sesudah pemasangan dapat timbul rasa nyeri seperti mules-mules kadang-kadang dapat menjadi rasa nyeri atau kram atau sakit pinggang terutama pada hari-hari pertama dan sesudah pemasangan, (2) rasa 
nyeri/mules pada waktu haid; sewaktu haid mulai terasa nyeri yang berlebihan, tak tertahankan, (3) nyeri pada senggama ; sewaktu senggama terasa nyeri dan (4) nyeri dapat timbul sewaktu-waktu selama masa pemakaian. Penyebabnya yaitu psikis, kemungkinan disebabkan letak IUD yang salah atau IUD tidak sesuai dengan rongga rahim dan IUD merangsang pembentukan prostaglandin pada waktu haid yang menimbulkan rasa nyeri

Penanggulangan dan pengobatan :

1. KIE (Komunikasi Informasi Edukasi)

a. Jelaskan penyebab terjadinya

b. Motivasi agar tetap memakai IUD

c. Memastikan penyebabnya dengan menganjurkan pemeriksaan dalam.

2. Tindakan medis

a. Inspekulo : apakah ada cairan keputihan yang berbau, erosi pada porsio.

b. Pemeriksaan dalam apakah terdapat tanda-tanda radang di rahim, bila terdapat tanda-tanda radang, AKDR harus segera dilepas, apabila pada pemeriksaan dalam terdapat benang AKDR terlalu panjang maka tindakannya adalah dengan memotong benang tersebut, nyeri dapat pula disebabkan oleh ekspulsinya AKDR

c. Bila diperlukan dapat diberi analgetik (salah satu) Asam mefenamat 3x 250$500 \mathrm{mg}$ perhari selama 3-5 hari atau antalgin 3x500 mg perhari selama 3-5 hari.

d. Kalau rasa nyerinya berat, sebaiknya diperiksa dokter, apakah IUD masih ada didalam rahim, bila IUD terlihat sedikit, berarti sebagaian sudah keluar, maka IUD dikeluarkan dan diganti dengan IUD yang baru, (DepKes RI, 2002).

Berdasarkan dari hasil penelitian pada bab 4 jumlah akseptor KB IUD yang tetap memakai sejumlah 15 orang $(48,39 \%)$ sedangkan yang memilih untuk drop out sejumlah 16 orang $(51,61 \%)$.

Faktor-faktor yang sangat mempengaruhi terjadinya pemutusan pemakaian kontrasepsi seseorang antara lain
1. Pengalaman ber KB

Pengalaman menggunakan salah satu alat kontrasepsi merupakan suatu faktor yang menunjang pemahaman tentang metode kontrasepsi tersebut pengalaman yang buruk seperti efek samping yang berat dari salah satu alat kontrasepsi akan menjadi alasan yang kuat untuk berhenti atau sebaliknya pengalaman yang baik akan dijadikan pendorong untuk mengulangi kontrasepsi yang pernah digunakan.

2. Peran pengambil keputusan

Persetujuan suami merupakan faktor paling penting dalam memutuskan untuk memakai atau tidak memakai kontrasepsi, wanita juga sering menjadi pihak yang disalahkan apabila terjadi kesalahan pemanfaatan pelayanan kesehatan karena pendidikan, kemiskinan dan motivasi yang rendah.

3. Adanya putus pakai

Berbagai alasan yang dikemukakan oleh para peserta KB mereka berhenti setelah 5 tahun pemakaian alasan utama mereka adalah karena ingin hamil, efek samping, masalah kesehatan, kegagalan, ingin ganti cara yang efektif.

4. Status sosial

Wanita dengan pendidikan yang lebih tinggi cenderung untuk melaporkan penerimaan informasi dan konsultasi yang lebih baik dibandingkan dengan wanita yang pendidikan lebih rendah, makin tinggi tingkat pengetahuan seseorang makin mudah menerima informasi tentang alat kontrasepsi.

5. Faktor demografi

Umur merupakan salah satu faktor yang mempengaruhi seseorang menjadi akseptor KB sebab umur berkaitan dengan potensial reproduksi dan masih dapat mempengaruhi akseptor dalam penggunaan kontrasepsi yang digunakan.

6. Tempat tinggal

Tempat tinggal individu berada akan sangat mempengaruhi pandangannya terhadap pelayanan-pelayanan sosial yang diberikan, wanita yang tinggal di perkotaan cenderung untuk memiliki pandangan dan perilaku yang berbeda terhadap kualitas pelayanan KB. 
7. Aktifitas dalam masyarakat

Salah satu strategi untuk memberdayakan wanita agar memiliki sikap memenuhi kebutuhan kesehatan reproduksi mereka adalah memberi dukungan dalam kegiatan pendidikan seperti perkumpulan kader-kader sehat, penyuluhan dan sebagainya sehingga menumbuhkan rasa percaya diri mereka sehingga mereka mampu untuk bertanya tentang masalah yang berkaitan dengan kebutuhan kesehatan mereka termasuk kebutuhan pemahaman reproduksi, (Widaningrum, 1999).

Penanganan akseptor KB IUD yang Drop out :

1. KIE

a. Kenalkan alat kontrasepsi lain

b. Jelaskan cara kerja masing-masing alat kontrasepsi

2. Anjurkan untuk memakai alat kontrasepsi sesuai pilihan ibu

3. Melakukan konsultasi dengan petugas kesehatan bila terjadi masalah.

Efek samping KB IUD (nyeri perut) merupakan salah satu dari efek samping penggunaan KB IUD, dalam masyarakat efek samping KB IUD (nyeri perut) menimbulkan persepsi yang negatif yaitu dianggap ketidakcocokan dalam penggunaan KB IUD. Pada dasarnya efek samping KB IUD (nyeri perut) merupakan hal yang biasa dan bisa diatasi apabila akseptor mau mengkonsultasikan masalah yang sedang dihadapi dengan tenaga kesehatan, karena tidak semua efek samping menimbulkan dampak yang serius terhadap kesehatan akseptor. Efek samping KB IUD (nyeri perut) bisa ditanggulangi sesuai keluhan akseptor dan diharapkan akseptor proaktif dalam hal ini, bila dalam proses penanggulangan efek samping menemukan masalah atau komplikasi maka IUD bisa dilepas sesuai indikasi yang terjadi, (Dep Kes RI, 2002).

Kelangsungan penggunaan KB IUD diikuti oleh tuntutan akan peningkatan kualitas pelayanan KB IUD dan pengayoman medisnya, tuntutan ini tentu saja harus dipenuhi agar kelestarian pemakaian KB IUD tetap terjaga. Untuk itu pengetahuan dan ketrampilan para petugas dalam pelayanan $\mathrm{KB}$ terutama $\mathrm{KB}$ IUD perlu ditingkatkan termasuk penanggulangan efek samping. Penanggulangan efek samping yang kurang benar dapat menimbulkan akibat yang tidak diinginkan seperti drop out dari program KB IUD dan timbulnya rumor/gosip yang berlebihan tentang program $\mathrm{KB}$.

\section{Kesimpulan}

Berdasarkan Analisa Uji Statistik Chi Kuadrat adalah efek samping KB IUD (nyeri perut) tidak ada hubungan yang signifikan dengan kelangsungan penggunaan KB IUD di wilayah kerja Puskesmas Wringin Kabupaten Bondowoso tahun 2015. Berdasarkan kesimpulan di atas maka tidak dilakukan uji Koefisiensi Kontingensi.

Untuk meningkatkan target program diharapkan dapat meningkatkan penyuluhan tentang KB IUD disertai dengan efek samping penggunaannya sehingga masyarakat tahu dan paham mengenai $\mathrm{KB}$ IUD sehingga tercapainya program $\mathrm{KB}$ terutama KB IUD

\section{Daftar pustaka}

BKKBN. 1999. Informasi Pelayanan Kontrasepsi. Jakarta

BKKBN. 2004. Peningkatan Partisipasi Pria dalam KB dan Kesehatan Reproduksi. Jakarta : BKKBN.

BKKBN. 2004. Gender dalam KB dan Kesehatan Reproduksi. Jakarta : BKKBN

Departemen Kesehatan RI. 2002. Pedoman Penanggulangan Efek Samping/Komplikasi Kontrasepsi. Jakarta : Depkes RI

Hartanto, hanafi. 2004. Keluarga Berencana dan Kontrasepsi. Jakarta : Pustaka Sinar Harapan.

Hasan, Iqbal, 2003. Pokok-pokok materi statistik 1 (Statistik Deskriptif), Jakarta : Bumi Aksara.

Lembaga Demografi FE UI, Dasar - dasar Demografi, Jakarta

Manuaba, Ida Bagus Gde, 2002. Ilmu kebidanan, penyakit kandungan dan Keluarga Berencana untuk pendidikan Bidan. Jakarta : EGC.

Notoatmodjo, Soekidjo. 2005. Metodelogi Penelitian Kesehatan. Jakarta : Rineka Cipta. 
ISSN : 2354-5852

e-ISSN : 2579-5783

Nursalam, 2003. Konsep dan Penerapan Metodelogi Penelitian Ilmu Keperawatan. Jakarta : Salemba Medika.

Saifuddin, 2003. Buku Panduan Praktis Pelayanan Kontrasepsi. Jakarta : Yayasan Bina Pustaka.

Widaningrum, Ambar. 1999. Kualitas Pelayanan Keluarga Berencana dalam Perspektif Klien. Yogyakarta :

Universitas Gadjah Mada. 